\title{
Research on the Application of Sense of School Belonging in Education Management Practice
}

\author{
Wenjie Huang \\ South China Normal University, Guangzhou, 510000, China
}

\begin{abstract}
Recently, people believe that the sense of school belonging is good for students to adjust themselves to the new conditions, improve their educational achievements and encourage their good attitudes. It has good application results in the education management practice. This paper analyzes the influence factors of school belonging and the cultivation methods of school belonging to provide some references for the relative researchers.
\end{abstract}

Keywords:education management, sense of school belonging, application

\section{Concept of school belonging and its important functions}

The sense of belonging refers to an internal relation between the individual and the group. It is a designation, identification and maintenance of a particular group and its subordinate relationship. The sense of belonging is the psychological performance of this designation, identification and maintenance. It belongs to the concept of cultural psychology, which refers to the degree of identity of an individual or group to an event or a phenomenon. Students' sense of belonging is the identification and correlation degree of the organization. A sense of belonging and a sense of security and acceptance of the person who loves you, there is a sense of community. The sense of security includes being taken care of, not worried, being protected. Increased sense of belonging can help reduce or even eliminate students' sense of alienation. It can positively affect students' confidence and sense of responsibility. The sense of belonging is a positive and positive attitude to the school. It is one of the most important psychological needs of middle school students. Schools have become one of the important places for students to study and live. And the sense of belonging to the school reflects the 
quality of life of the middle school students. Students have a sense of belonging will enhance the quality of campus life. Students have a sense of belonging to the school, which indicates that the students' campus life is joyful and meaningful.

\section{Influence factors of school belonging}

\subsection{Campus culture}

Campus culture refers to the overall impact of social culture, which can reflect the fine tradition of the nation, with a new spirit of the times and the school's personality. School culture is the inner motive force of the development of the school. School culture is the driver of the development of the school to stimulate the subjective initiative and play a role. The development of modern education shows that traditional school resources may not be able to win in the fierce competition in the education market, only those who have mastered the technology of modern education, with distinctive culture characteristics of the school. It has a genuine competitive advantage. If complemented by appropriate incentives and stable employment security, collective identity and personal ownership of good, the sense of accomplishment and self-realization of the value of the magnetic field to maintain power. We put them together in order to establish harmonious interpersonal relationship and unity of trust and understanding in the campus, and achieve the target of truth and the consensus and the pursuit of the school. Only the excellent school culture can nurture excellent school education. In order to form the correct life of students, the values and the world outlookshould be practiceduntil the students studying timber and life success.

\subsection{Education model}

At present, our country's education is also the exam oriented education. The most important task is to learn in school students, schools and teachers emphasize the scores and graduation rates, so many high school courses have no sports, art and music course. Rural middle schools are lack of educational resources and excellent teachers. Many students in the choice of junior high school settled on the school's reputation, the family will be around the city children's education to the housing, many families to be able on the famous middle school and continue to move. The rural family also appeared accompanying phenomenon, working with children go to school in the city of variable edge, which caused the school pressure, no ordinary middle school students. A dominant effect and recessive influence is shocking, whether parents consider the child's feelings or not. The child can integrate into the environment, whether a healthy and meaningful life. Serious damage to extracurricular activities overburdening, lack of physical and mental health of students, but also greatly reduce the students' sense of belonging to the school. Many students think that the memory of childhood is learning, and constantly learning. This kind of education mode hinders the formation of the sense of belonging to the school to a certain extent. 


\subsection{Teacher-student relationship}

The bad relationship between teachers and students can make the students hate school, truancy, vandalism and contradict the teacher status, leading the negative emotional resistance to the school. There is a heavy burden on the spirit of the burden of the students, to give more encouragement and support. Students in the school, they most admire is the teacher, but the most difficult to communicate is also a teacher. Because in the eyes of the teacher only those students with good grades, but ignore the poor students, for outstanding students and teachers will greatly praise, while the poor students will be scolded or hurtful words. They all express a kind of voice, if the teacher can understand them more, communicate with them, students will not be afraid of the teacher, will take the initiative to communicate with the teacher, teachers and students to form a harmonious relationship between teachers and students. Teachers usually pay more attention to good grades of students, the main focus on the good performance of the students, the class learning achievement is not good students are a state of stocking. If teachers use this kind of attitude to treat students, the harmonious relationship between teachers and students is destroyed in the invisible. Middle school students will also because of the teacher's words and deeds and the emergence of niche phenomenon, the communication between teachers and students invisible fusion penetration more utilitarian color. Some of the outstanding students of the school more love, a sense of belonging. These conditions will inevitably lead to the lack of students' sense of belonging.

\section{Cultivation methods of school belonging}

\subsection{Construct positive campus culture}

We can exert the positive influence function of campus culture. The campus culture has profound influence on psychology, personality and behavior rules of campus. The main form of campus culture is the school spirit, teaching style, study style, moral behavior and system culture atmosphere. Interview students reflect the main problems are: the school learning atmosphere, the various problems of the school management. Therefore, the school should pay attention to the good guidance, to strengthen the school study style, teaching style construction. To let students participate in activities is an effective way to enhance the feelings, in the activities of the establishment of the feelings is relatively stable. According to the specific circumstances of the school, we should cultivate students' sense of identity and sense of belonging, through a number of symbolic activities, but also through a variety of cultural activities organized by the school to form. These activities can give people a deep impression, so that students and teachers to communicate with each other to enhance the sense of belonging to the school. Only in this way can students feel satisfied, thus it is conducive to the formation of students' sense of belonging. Schools should focus on spiritual and cultural construction. We strengthen the humanistic spirit, to carry out the cultural characteristics of the school. Schools 
should allow students to take the initiative to participate in the construction of campus culture, innovative campus culture, to stimulate the initiative of students. In the construction of campus culture, dig the school's own characteristics, cultivate students' unique humanistic temperament, so that students can face thelife and learning with a positive attitude.

\subsection{Construct reasonable education model}

Increasing students' autonomous learning space is an important way to improve students' sense of belonging. A student of course cannot do without the guidance of teachers, explaining and answering questions, but more important is learning to digest the classroom content. Although the remedial teachers work overtime, very hard, but this kind of teaching method takes up a large number of students autonomous learning time, students are forced to only lectures, lectures, and lectures. They don't have time to digest and have no time to think, no time to prepare the review, no time to fill gaps. Therefore, this teaching method is inefficient. All the teachers need to explain the content in normal classes, weekend and evening time for students' Autonomous learning. Students in autonomous learning attitude when input, thinking is active, they adjust their learning content according to their own situation, learning methods, thinking about the learning of the knowledge in class. This method of active learning, learning and thinking is conducive to reduce the academic burden on students, help students arrange teaching contents, to improve learning efficiency, to enhance the sense of belonging to the school. The school held a school where the students of all activities required participating in person, so that they put these activities as their own thing, the school as their home. Education reform should focus on quality education. The purpose of reform should be to improve the overall quality of students, not only the pursuit of enrollment rate. Education should pay more attention to the quality of living. Sense of belonging education is a long-term education link. It is also a new direction of economic development under the new normal education.

\subsection{Construct harmonious teacher-student relationship}

The cultivation of students' sense of belonging is very important in the current school work. The teacher should not only from the external input some ideas for students to accept, but also to understand the psychological development of students from the inside, dig out the good thoughts of seeds from their soul, use the existing student ideological and political education to cultivate the soil, rooted in back to the original student psychology, so the ideological and political education effect is ideal, in the minds of the students is easy to grow. Therefore, teachers should take various forms to cultivate students' sense of belonging, and complete the task of teaching and educating. Teachers in the face of the new situation and new subjects are to change the traditional education ideas and concepts, should be more concerned about and help students to establish a harmonious relationship between teachers and students. School interpersonal relationship includes two aspects, namely, the relationship between teachers and 
students, the relationship between students and students. The relationship between students and students is well established, but the establishment of the relationship between teachers and students is more difficult. The harmonious relationship between teachers and students can make students more trust and rely on the teacher, help students form the positive emotion of the school, which will help students have a good adaptation in school.

\section{Conclusion}

The cultivation of school belonging sense is an important part of the practice of education management. A school should cultivate the sense of school belonging of all the students in the school. Sense of belonging is not born. It is slowly developed out in the student's life in the school. The positive campus culture, the reasonable education model and the harmonious teacher-student relationship are the basis of the school belonging formation.

\section{References}

[1] Yu Lixin, The Continuing Education Student s Sense of School Belongingand the Application of Library Resources, Journal of China Institute of Industrial Relations, 25(11), pp. 119-121, 2011.

[2] Tang Xiumei, The Study of Normal University Students Senseof School Belonging and Affecting Factors, Heilongjiang Researches on Higher Education, 34(7), pp. 85-88, 2015.

[3]Li Qiaoling, Wang Junyou, Wang Minghui, The Effect of Campus Culture on the Students School Belonging:Based on the Analysis of Hierarchical Linear Model, Journal of North China University of Water Resources and Electric Power (Social Science Edition), 30(6), pp. 158-160, 2014.

[4]ShuiYuanxuan,

TheInvestigativeJournalismontheSenseofSchoolBelongingofCollegeStudentsBelo ng toNanjing, 31(8), pp. 105-109, 2015. 